\title{
IDENTIFICATION OF E6A2 BCR-ABL FUSION IN A PHILADELPHIA-POSITIVE CML WITH MARKED BASOPHILIA: IMPLICATIONS FOR TREATMENT STRATEGY
}

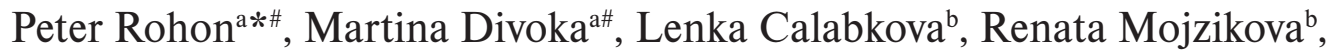 \\ Beata Katrincsakova ${ }^{a}$, Zuzana Rusinakova ${ }^{a}$, Anna Lapcikova ${ }^{a}$, Ludek Raida ${ }^{a}$, Edgar Fabera \\ Marie Jarosova ${ }^{\mathrm{a}}$, Vladimir Divoky ${ }^{\mathrm{b}}$, Karel Indrak ${ }^{\mathrm{a}}$
}

\author{
a Department of Hemato-Oncology, University Hospital Olomouc and Faculty of Medicine and Dentistry, Palacky University \\ Olomouc, Czech Republic \\ ${ }^{b}$ Department of Biology, Faculty of Medicine and Dentistry, Palacky University Olomouc \\ \# Authors contributed equally to this work \\ E-mail: peter.rohon@centrum.cz
}

Received: March 1, 2011; Accepted with revision: April 29, 2011

Key words: Chronic myeloid leukemia (CML)/e6a2 BCR-ABL fusion/Basophilia/Tyrosine kinase inhibitors (TKIs)

Aim. This is a case report of a 51 year old male with marked splenomegaly, basophilia, severe thrombocytopenia, anemia and high SFKL phosphorylation downstream of Bcr-Abl, investigated for association of the e6a2 $B C R-A B L$ fusion gene and marked basophilia. The treatment strategy implications in patients with Philadelphia positive CML are described.

Methods. RT-PCR and sequencing were carried out on the peripheral blood leukocytes to detect the type of $B C R$ $A B L$ transcript. The $B C R-A B L$ mutational status was assessed using sequencing of the RT-PCR products. The in vitro test of sensitivity to TKIs was based on detecting inhibited phosphorylation of the Crkl and Phospho-Src family kinases (SFK, Tyr416) using immunodetection.

Results. The cytogenetics revealed $90 \%$ of $\mathrm{Ph}+$ (Philadelphia) cells in the bone marrow aspirate with no additional clonal chromosomal abnormalities at diagnosis. This correlated with an accelerated phase of the CML. Sequencing analysis of reverse transcribed and PCR amplified $B C R-A B L$ transcript revealed a rare e6a2 fusion, with no evidence for Bcr-Abl kinase domain mutation. Western blot analysis showed high phosphorylation (activation) of Crkl and the Src family of kinases (P-SFK). In vitro test of sensitivity of the patients' leukemic cells to imatinib demonstrated sensitivity of Bcr-Abl tyrosine kinase to imatinib, as assessed by a decrease in phosphorylated Crkl and the disappearance of P-SFK, suggesting that P-Src reflects only the Bcr-Abl-dependent Src activity. The initial treatment strategy was reduced imatinib and search for an unrelated hematopoietic stem cell donor (according to the ELN recommendations). The patient was allografted with peripheral stem cells from an HLA- identical male donor but on day +70 graft failure occurred. He was allografted again with the peripheral stem cells from an HLA-identical female donor, engrafted on day +15 and showed $100 \%$ donor chimerism with no evidence of the e $6 \mathrm{a} 2 B C R-A B L$ fusion transcript on day +30 . Conclusion. The clinical disease course in patients with the rare e6a $2 B C R-A B L$ transcript variant is aggressive. This may be the result of increased kinase activity due to partial loss of the guanine exchange factor/dbl-like domain which mediates the interaction with several Ras-like G-proteins involved in cell proliferation, signal transduction, and cytoskeletal organization. For the above reasons, these patients should receive stem cell transplant immediately after a short course of treatment with imatinib/ dual Src/Abl kinase inhibitor or they should be registered in clinical trials with experimental agents.

\section{INTRODUCTION}

In over $95 \%$ of cases, the first step in the pathogenesis of chronic myeloid leukemia (CML) is the formation of the Philadelphia $(\mathrm{Ph})$ chromosome. This is due to reciprocal translocation between chromosomes 9 and 22, designated $\mathrm{t}(9 ; 22)(\mathrm{q} 34 ; \mathrm{q} 11)$, which is associated with de novo formation of the $B C R-A B L$ fusion oncogene and oncoprotein with increased tyrosine kinase activity ${ }^{1}$. The $5^{\prime}$ region of $B C R-A B L$ oncogene consists of exons derived from the $B C R$ gene, and the $3^{\prime}$ part contains sequences of the $A B L$ gene. The breakpoint in the $A B L$ gene is relatively constant and occurs in exon 2 (a2); however, one known exception to the $A B L$ gene breakpoint location is exon 3 (a3) (ref. ${ }^{2}$ ). In most CML patients, the breakpoint on the $B C R$ gene occurs in the major breakpoint cluster region (M-BCR), leading to b2a2 (e13a2) or b3a2 (e14a2) fusion transcripts that are translated into the p210 kDa Bcr-Abl protein. Breakpoints outside $\mathrm{M}-\mathrm{BCR}$ are extremely rare in CML. In contrast, the m-BCR (minor) breakpoint, producing the e1a2 fusion transcript and a p190 kDa fusion protein, is reported in patients with Ph-positive acute lymphoid leukemia ${ }^{3}$. Other atypical $B C R-A B L$ transcripts with fusions, such as e8a 2 or e6a 2 , are very rare and have only 
been occasionally described ${ }^{4}$. The $B C R-A B L$ transcript e $6 \mathrm{a} 2$ has been reported in CML cases with aggressive clinical courses ${ }^{5-7}$ and in acute basophilic leukemia ${ }^{8}$.

\section{MATERIAL AND METHODS, RESULTS}

\section{Patient's characteristics}

We describe a 51-year-old male patient previously in good health who presented in January 2010 with marked splenomegaly (12 cm under costal margin), a history of abdominal discomfort lasting 3 weeks, weight loss and night sweats. His peripheral blood showed a hemoglobin concentration of $73 \mathrm{~g} / 1$ and a platelet count of $36 \times 10^{9} / 1$. His white blood cell (WBC) count was $150 \times 10^{9} / 1$ and consisted of $45 \%$ basophils, $18 \%$ eosinophils, $18 \%$ neutrophils, $2 \%$ lymphocytes, $4 \%$ metamyelocytes, $5 \%$ myelocytes, $6 \%$ promyelocytes and $2 \%$ myeloblasts. The patient's severe anemia and thrombocytopenia did not cause any clinical complications. The morphology of his bone marrow aspirate corresponded to the findings in the peripheral blood (Fig. 1). Standard cytogenetics which examined the G-banding pattern, confirmed a typical $\mathrm{t}(9 ; 22)(\mathrm{q} 34 ; \mathrm{q} 11)$ translocation in all 10 examined metaphases, with no additional chromosomal abnormalities. $B C R-A B L$ fusions were identified in $90 \%$ of bone marrow WBCs using interphase fluorescence in situ hybridization (iFISH) (ref. ${ }^{9}$ ) (278 BCR-ABL+ nuclei in a total of 308 examined nuclei). Marked basophilia suggested the patient was in the accelerated phase of CML. The patient's risk was intermediate according to his Sokal score ${ }^{10}$. However, according to his Hasford score ${ }^{11}$, he was in the high-risk group.

\section{Molecular analysis}

The initial $B C R-A B L$ analysis was carried out on peripheral blood leukocytes as previously described ${ }^{12}$.

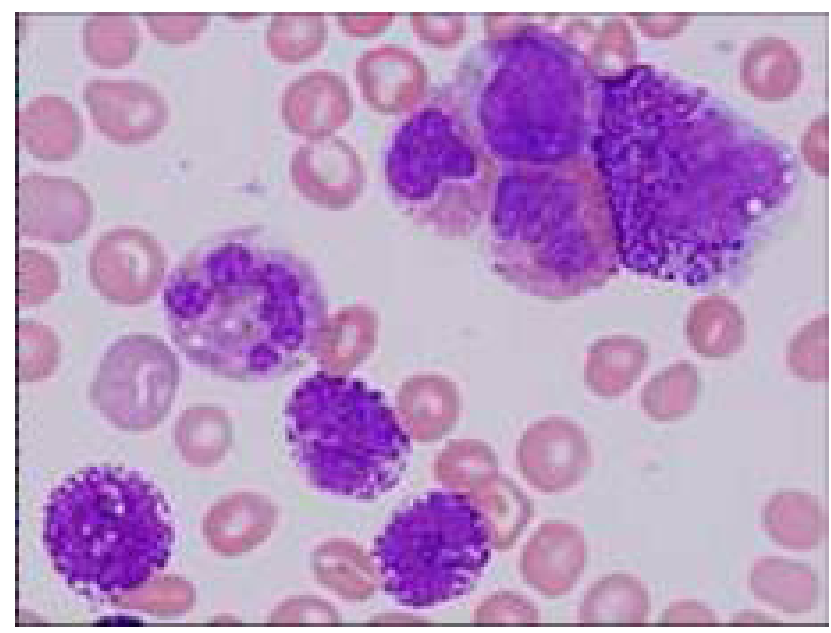

Fig. 1. Hypercellular bone marrow aspirate with predominance of granulopoiesis at the time of diagnosis. The number of myeloblasts was not elevated. There was an increased population of basophils, including their immature forms. The number of eosinophils was increased as well.
Nested reverse transcriptase-polymerase chain reaction (RT-PCR) for e 1a2 (minor $B C R-A B L$ ) and e $13 \mathrm{a} 2$ or e14a2 (major $B C R-A B L$ ) fusion transcripts yielded negative results. Because iFISH for $B C R-A B L$ (ref. ${ }^{13}$ ) was positive, another RT-PCR for a rare e6a2 $B C R$ $A B L$ fusion transcript was performed (forward primer: 5'-GACTTACCTGAGCCACCTGGA G-3', reverse primer: 5'-GTTTGGGCTTCACACCATTCC-3'). The amplified cDNA product was sequenced with both the forward and reverse primers used for RT-PCR. Sequencing analysis confirmed a rare e6a2 $B C R-A B L$ fusion transcript (Fig. 2). There was no evidence of a $B C R-A B L$ kinase domain mutation using sequencing analysis as previously described ${ }^{14}$. Western blot analysis showed high phosphorylation (activation) of the Crkl and the Src family of kinases (P-SFK). An in vitro test of the patients' leukemic cell sensitivity to TKI, after incubating with or without $10 \mu \mathrm{M}$ imatinib, demonstrated sensitivity of Bcr-Abl tyrosine kinase to imatinib $^{13,15}$. This was assessed by a decrease in phosphorylated Crkl and the disappearance of P-SFK, suggesting that the P-Src reflects only the Bcr-Abl-dependent Src activity (Fig. 3).

\section{Treatment}

The initial cytoreduction was performed with a daily dosage of $6 \mathrm{~g}$ of hydroxyurea that was administered with standard therapy to prevent the tumour lysis syndrome. After 7 days of cytoreduction, imatinib therapy was initiated at a reduced daily dosage of $400 \mathrm{mg}$ due to the patient's severe thrombocytopenia. The imatinib-induced neutropenia that occurred 2 weeks after the initiation of treatment with imatinib led to the introduction of therapy with G-CSF and anti-infective prophylaxis. One transfusion unit of platelets was administered because of cutaneous petechiae. The imatinib therapy was limited to 5 days per week. While drug therapy was ongoing, a search for an unrelated hematopoietic stem cell donor was initiated, as no suitable donor was identified in the patient's family. After 3 months of treatment with imatinib, the patient did not achieve any hematologic response, as there was a persistence of basophilia in the peripheral blood and bone marrow. Nor did the patient achieve a cytogenetic response, as the $\mathrm{Ph}$ chromosome was found in all 12 metaphases analyzed. After the identification of a suitable donor, the patient was allografted with peripheral stem cells from an HLA-identical male donor after a conditioning regiment of Flu+Bu12+ATG (fludarabine, busulphan 12mg/ $\mathrm{kg}$, antithymocytic globuline) in June 2010. Graft-versushost disease (GVHD) prevention was achieved with the cyclosporine A therapy. The posttransplantation course was complicated by grade 1 mucositis, grade 1 renal insufficiency and a fever of unknown origin. The patient showed $90 \%$ donor chimerism in the peripheral blood on day +15 and was engrafted again on day +18 after transplantation. Further chimerism analysis showed $96 \%$ donor hematopoiesis in the marrow on day +28 . A check of the bone marrow on day +50 showed hypocellularity with a decreased basophil count of $1 \%$ and regeneration changes. Standard cytogenetic analysis was not available 


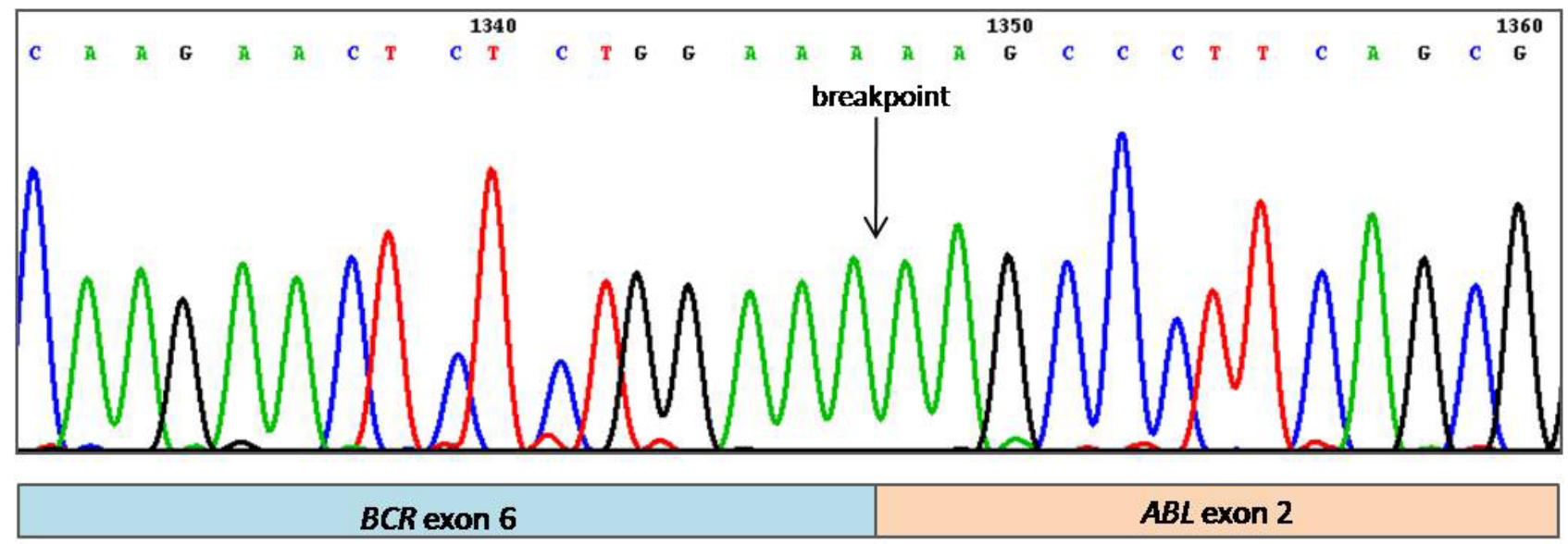

Fig. 2. Sequencing analysis confirmed a rare e6a2 $B C R-A B L$ fusion transcript.

due to cultivation failure. However, the e6a2 $B C R-A B L$ fusion gene was present in the second round of nested RT-PCR. Clinically, there was no evidence of GVHD, and the dose of cyclosporine A was reduced. However, on day +70 , the patient experienced pancytopenia. The bone marrow examination showed only $47 \%$ donor chimera, suggesting that a graft failure had occurred. Despite the withdrawal of cyclosporine A and growth factors, an attempted rescue of the graft failed, possibly due to EpsteinBarr virus (EBV) reactivation and gradually increasing number of EBV DNA copies in plasma. Anti-CD20 monoclonal antibody (rituximab) was administered to prevent the development of EBV-associated lymphoproliferative disease in a severely immunocompromised host. Only one administration of rituximab led to a complete resolution of EBV DNA in the recipient plasma. Nevertheless, the patient required a second transplant from another donor. After identification of a suitable alternative donor, the patient was allografted with peripheral stem cells from HLA-identical female donor after a conditioning regimen of Flu+CTX+LD-TBI (fludarabine, cyclophosphamide, low dose total body irradiation) in September 2010. Prevention of GVHD was achieved again with cyclosporine A. The patient was engrafted again on day +15 and showed $100 \%$ donor chimerism. There was no evidence of the presence of the e6a2 $B C R-A B L$ fusion transcript when testing the bone marrow using nested RT-PCR on day +30 after the second transplant.

\section{DISCUSSION AND CONCLUSION}

The presence of atypical, shorter $B C R-A B L$ transcripts in CML is associated with an aggressive clinical course $^{5-8,16,17}$. It has been suggested that the poor clinical outcome associated with the e6a2 Bcr-Abl protein could be the result of increased kinase activity due to the partial loss of the guanine exchange factor/dbl-like domain ${ }^{6}$. This domain, also completely absent in the p190 Bcr-Abl protein, mediates the interaction with several Ras-like G-proteins involved in cell proliferation, signal trans-

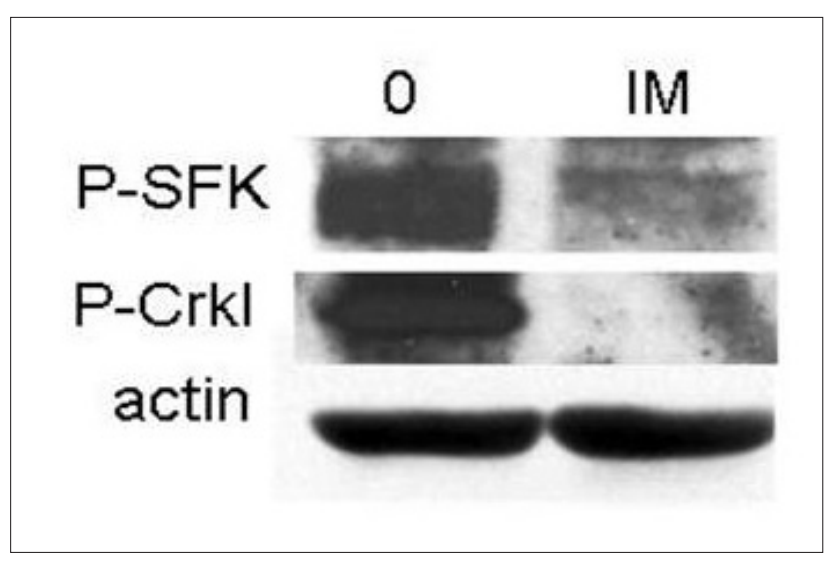

Fig. 3. High phosphorylation of SFK and Crkl as detected by Western analysis in the the patient's leukemic cells at the time of diagnosis. Without the addition of imatinib (0) both phosphorylated proteins (P-SFK and P-Crkl) were detected. Incubation with imatinib (IM; $10 \mu \mathrm{M})$ in vitro inhibited the phosphorylation of Crkl and SFK. $\beta$-actin was used as a gel loading control.

duction, and cytoskeletal organization ${ }^{18,19}$. The patient described here adds to our knowledge of e6a2-associated CML. He presented with marked splenomegaly, basophilia, severe thrombocytopenia, anemia and a high phosphorylation of SFK downstream of Bcr-Abl. In agreement with other authors, we believe that patients with the rare e6a2 $B C R-A B L$ transcript variant encoding Bcr-Abl kinase, possibly with enhanced oncogenic potential, cannot be treated with standard imatinib therapy. Instead, they should receive a stem cell transplant right away after a short course of treatment with imatinib or with a dual $\mathrm{Src} / \mathrm{Abl}$ kinase inhibitor or, they should be registered in clinical trials with experimental agents. 


\section{ACKNOWLEDGEMENTS}

This research was supported by the Ministry of Health of the Czech Republic (grant NS 9949-3), by student project LF_2011_006 of Palacky University, by Bristol-Myers Squibb Research Grant (to V.D.) and by the grant MSM 6198959205 of the Ministry of Education, Youth and Sports of the Czech Republic. We would like to thank the personnel at the Laboratory of Cytogenetics and at the Laboratory of Molecular Genetics at the Department of Hemato-Oncology for their expert technical assistance.

\section{REFERENCES}

1. Deininger MW, Goldman JM, Melo JV. The molecular biology of chronic myeloid leukemia. Blood 2000;96:3343-56.

2. Melo JV. The discovery of BCR-ABL fusion proteins and their relationship to leukemia phenotype. Blood 1996;88:2375-84.

3. Hermans A, Heisterkamp N, von Lindern M, Baal S, Meijer D, van der Plas D, Wiedemann LM, Groffen J, Bootsma D, Grosveld G. Unique fusion of bcr and c-abl genes in Philadelphia chromosome positive acute lymphoblastic leukemia. Cell 1987;51:33-40.

4. Branford S, Rudzki Z, Hughes TP. A novel BCR-ABL transcript (e8a2) with the insertion of an inverted sequence of ABL intron $1 b$ in a patient with Philadelphia-positive chronic myeloid leukaemia. Br J Haematol 2000;109:635-7.

5. Dupont M, Jourdan E, Chiesa J. Identification of e6a2 BCR-ABL fusion in a Ph-positive CML. Leukemia 2000;14:2011-2.

6. Schultheis B, Wang L, Clark RE, Melo JV. BCR-ABL with an e6a2 fusion in a CML patient diagnosed in blast crisis. Leukemia 2003; 17:2054-5.

7. Colla S, Sammarelli G, Voltolini S, Crugnola M, Sebastio P, Giuliani N. e6a2 BCR-ABL transcript in chronic myeloid leukemia: is it associated with aggressive disease? Haematologica 2004;89:611-3

8. Gregoire MJ, Latger-Cannard V, Staal A, Bologna S, Leotard B, Rault JP, Bery-Dexheimer M, Jonveaux P. Identification of an acute basophilic leukaemia carrying a rare e6a2 BCR-ABL transcript. Acta Haematol 2006;116:216-8.

9. Holzerova M, Faber E, Veselovska J, Urbankova H, Balcarkova J, Rozmanova S, Voglova J, Muzik J, Chroust K, Indrak K, Jarosova M. Imatinib mesylate efficacy in 72 previously treated Philadelphiapositive chronic myeloid leukemia patients with and without additional chromosomal changes: single-center results. Cancer Genet Cytogenet 2009;191:1-9.
10. Sokal JE, Cox EB, Baccarani M, Tura S, Gomez GA, Robertson JE, Tso CY, Braun TJ, Clarkson BD, Cervantes F. Prognostic discrimination in ,good-risk“ chronic granulocytic leukemia. Blood 1984;63:789-99.

11. Hasford J, Pfirmann M, Hehlmann R, Allan NC, Baccarani M, Kluin-Nelemans JC, Alimena G, Steegmann JL,Ansari H. A new prognostic score for the survival of patients with chronic myeloid leukemia. J Natl Cancer Inst 1998;90:850-8.

12. van Dongen JJ, Macintyre EA, Gabert JA, Delabesse E, Rossi V, Saglio G, Gottardi E, Rambaldi A, Dotti G, Griesinger F,Parreira A, Gameiro V, Gonzalez Diaz A, Malec M, Langerak AW, San Miguel JF, Biondi A. Standardized RT-PCR analysis of fusion gene transcripts from chromosome aberrations in acute leukemia for detection of minimal residual disease. Report of the BIOMED-1 Concerted Action: investigation of minimal residual disease in acute leukemia. Leukemia 1999;12:1901-28.

13. Faber E, Nausova J, Jarosova M , Egorin MJ, Holzerova M, Rozmanova S, Maresova I, Divoky V, Indrak K. Intermittent dosage of imatinib mesylate in CML patients with a history of significant hematologic toxicity after standard dosing. Leuk Lymphoma 2006;47:1082-90.

14. Faber E, Friedecky D, Micova K, Divoka M, Katrincsakova B, Rozmanova S, Jarosova M, Indrak K, Adam T. Imatinib dose escalation in two patients with chronic myeloid leukemia, with low trough imatinib plasma levels measured at various intervals from the beginning of therapy and with suboptimal treatment response, leads to the achievement of higher plasma levels and major molecular response. Int J Hematol 2010;91:897-902.

15. Faber E, Mojzikova R, Plachy R, Rozmanova S, Stastny M, Divoka M, Jarosova M, Indrak K, Divoky V. Major molecular response achieved with dasatinib in a CML patient with F317L BCR-ABL kinase domain mutation. Leuk Res 2010;34:91-93.

16. Hochhaus A, Reiter A, Skladny H, Melo JV, Sick C, Berger U, Guo JQ, Arlinghaus RB, Hehlmann R, Goldman JM, Cross NC. A novel BCR-ABL fusion gene (e6a2) in a patient with Philadelphia chromosome-negative chronic myelogenous leukemia. Blood 1996;88:2236-40

17. Roti G, La Starza R, Gorello P, Gottardi E, Crescenzi B, Martelli MF, Mecucci C. e6a2 BCR/ABL1 fusion with cryptic der(9) $\mathrm{t}(9 ; 22)$ deletions in a patient with chronic myeloid leukemia. Haematologica 2005;90:1139-41.

18. Laurent E, Talpaz M, Kantarjian H, Kurzrock R. The BCR gene and Philadelphia chromosome-positive leukemogenesis. Cancer Res 2001;61:2343-45.

19. Ritchie SD, McBean M, Westerman DA, Kovalenko S, Seymour JF, Dobrovic A. Complete molecular response of e6a2 BCR-ABLpositive acute myeloid leukemia to imatinib then dasatinib. Blood 2008;111:2896-98. 